$$
\overbrace{1682}^{2}
$$

Germanistische Abhandlungen

Das Junge Deutschland 


\section{Das Junge Deutschland}

ANALYSE SEINES

SELBSTVERSTÄNDNISSES

J. B. METZLERSCHE

VERLAGSBUCHHANDLUNG

STUTTGART 
Germanistische Abhandlungen 33

ISBN 978-3-476-99740-1 ISBN 978-3-476-99739-5 (eBook)

DOI 10.1007/978-3-476-99739-5

Das Buch hat der Philosophischen Fakultät der Universität Bonn I 967/68 als Habilitationsschrift vorgelegen.

(C) Springer-Verlag GmbH Deutschland 1970

Ursprünglich erschienen bei J. B. Metzlersche Verlagsbuchhandlung und Carl Ernst Poeschel Verlag GmbH in Stuttgart 1970 
Benno von Wiese

DANKBAR GEWIDMET 


\section{INHALT}

\section{Vorbemerkung}

I: Das Junge Deutschland - Schulbegriff und bistorisches Pbänomen . . . . . . I

Der Bundestagsbeschluß vom ro. Dezember I 835 und seine Folgen I - Der Name "Junges Deutschland« 7 - Heine und Gutzkow 9 - Die soziologische Struktur des Jungen Deutschland I I - Börne und Heine I5 - Die »Bewegung «: die »Chorführer « und der Umkreis 20 - Das Junge Deutschland und die Politik 27 - Atheismus, Immoralismus, Saint-Simonismus 33 - Vorgeschichte des Bundestagsbeschlusses 36 - Engels' Fehlurteil 4I - Eigentliche Gemeinsamkeiten: der Generationskonflikt und seine spezifische Natur 42 - Die jungdeutschen Journale $45-$ Die »Tendenz« des Jungen Deutschland 52 - Der Zeitraum 53

$I I:$ Der Schriftsteller - Phänotyp der Moderne ................ ss

Literatur als Vermittlung zwischen Kunst, Wissenschaft und Leben 56-Der neue »Stil« als Ausdruck der Umorientierung zum »Leben« s8 - Die erzwungene Literarisierung der jungdeutschen Bestrebungen 60 - Literarische Formen des Jungen Deutschland 63 - Die Prosa 64 - Literatur als Historiographie 66 - Die Memoiren 68 - Das Junge Deutschland und die klassischen Literaturgattungen $70-$ Der Dichter als Schriftsteller 72 - Das neue schriftstellerische Selbstverständnis 74 Der Schriftsteller als Repräsentant seiner Zeit 78

$I I I$ : Zeitanalyse, Zeitbewußtsein, Zeitverständnis ........... 8 I

Die Bedeutung der »Zeit« 8 I - Die Widersprüche und Gegensätze der Zeit 83 Der geistesgeschichtliche Hintergrund 87 - Die politische Konstellation 88 Das Selbstverständnis der Zeit 90 - Bilder von Meerfahrt und Morgenrot als zentrale Metaphern der Zeit 92 - Möglichkeiten und Gefährdungen der Gegenwart 96 - Zukunftsutopien 99 - Das achtzehnte Jahrhundert im Zeitbewußtsein des Jungen Deutschland 102 - Ursprünge der jungdeutschen Bewegung 106 - Die Überschätzung der Gegenwart ro9 - Hamlet als Selbstporträt der jungdeutschen Epoche i i I 
Inhalt

IV: Das Junge Deutschland und Goethe: Versuch einer Emanzipation . . . . . . Ir4

Der literarische Beginn des neunzehnten Jahrhunderts I I4 - Goethes Tod i Is Wirkungen Goethes I 17 - Börne und seine Emanzipation von Goethe als seinem Antitypus I I9- Heine und seine Emanzipation von Goethe als seinem Rivalen I 22 - Die Goethekritik der übrigen Jungdeutschen I 26 - Goethe als »Zeitablehnungsgenie« r 27 - Goethes Indifferentismus und der demokratische Ansatz der jungdeutschen Goethekritik I 28 - Der monologische Charakter der jungdeutschen Goethekritik I 29 - Das Ende der »Kunstperiode« I 30

$V: » N e u e$ Klassizität«? - Jungdeutsche Versuche der Synthese . . . . . . . I 32

Der junge und der klassische Goethe im Urteil der Jungdeutschen 132 - Die Identifikation mit dem jungen Schiller 133 - Die Bedeutung des Goetheschen Kunstprinzips für das Junge Deutschland 134 - Ein Satz Heines I 34-Die Anerkennung Goethescher Kunstmaximen trotz der Kritik an Goethes Person 137 - Gutzkows Essay Über Goethe im Wendepunkte zweier Jabrbunderte und sein Bemühen um eine neue Klassizität I4I - Wienbargs Ästhetische Feldzüge und Goethes Organismusvorstellungen 143 - Die Problematik der jungdeutschen Synthesen 146 - Jean Paul als jungdeutscher Klassiker 149

VI: Das Junge Deutschland und die Romantik: Widersprüche und Kongruenzen .

Die Romantik-Kritik als Kritik an der Restauration I53 - Gründe der Gegnerschaft I 54 - Die Stellung Tiecks I s s - Heines Urteil über die Romantik I 6 - Friedrich und August Wilhelm Schlegel 157 - Übereinstimmungen mit der jungdeutschen »Tendenz«: das Junge Deutschland und die romantische Theorie der Vereinigung von Wissenschaft und Kunst 16I

\section{VII: Das Junge Deutscbland und die Geschichte: Systemkritik und Herder-Re-}

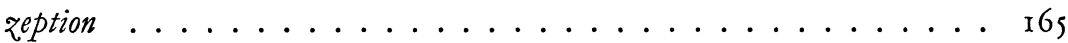

Der Gegensatz von klassischer, romantischer und jungdeutscher Geschichtskonzeption 165 - Die jungdeutsche Kritik an Hegels Geschichtsphilosophie ${ }_{167}$ Heines Verschiedenartige Geschichtsauffassung $\mathrm{I}_{7}$ - Die jungdeutsche Kritik an »System« und »Prinzip« 169 - Der »Unfug Historie« und die Individualität in der Geschichte 170 - Übereinstimmungen mit Ranke und der Frühromantik I 7 I - Die Herder-Rezeption der Jungdeutschen I 7 I - Unterschiede zur Herderschen Geschichtskonzeption 173 - Schlußwort 175

Anmerkungen ......................... I

Namenregister....................... 220 
Das Junge Deutschland ist auf der literarischen Landkarte seit langem keine unentdeckte Provinz mehr. Seit der Darstellung von Proelß, seit Houbens Jungdeutschem Sturm und Drang ist die Literatur des Jungen Deutschland gründlich nach allen Seiten hin durchforscht worden. Dutzende von Dissertationen wurden geschrieben, die Zugehörigkeit oder auch Nichtzugehörigkeit einer ganzen Reihe von Autoren zum Jungen Deutschland erörtert. Erst in den dreißiger Jahren verebbte diese Flut aus naheliegenden Gründen. Aber auch nach 1945 erschienen Arbeiten zum Jungen Deutschland. Die Wortforschung interessierte sich für sein sprachliches Material, die Literaturgeschichte für die Formensprache der Literatur dieser Zeit [x]. Von marxistischer Seite her fesselte das Phänomen nicht weniger, sah man hier doch revolutionäre Bestrebungen am Werk, die auf größere soziale Umwälzungen der Zeit hinzudeuten schienen.

Dennoch: wir wissen trotz allem immer noch sehr wenig über das Junge Deutschland. Das liegt zum Teil an der Konzeption der vorangegangenen Forschungen. Die früheren Arbeiten, vor allem die von Houben, haben in erster Linie biographische Einzelheiten zu ermitteln gesucht: Houbens große Darstellung über den Jungdeutschen Sturm und Drang gliederte sich bezeichnenderweise denn auch in Kapitel über einzelne Repräsentanten des Jungen Deutschland und verfolgt die persönlichen Lebensumstände und Querbeziehungen, um das Junge Deutschland derart dem Leser nahezubringen. $» D i e$ biographische, miterlebende Methode, aus der auch dieses mein Buch hervorgegangen ist, erscheint mir in jedem Fall als die unentbehrlichste Voraussetzung jeder anderen«, schrieb Houben an versteckter Stelle seines Werkes [2]. So verdienstvoll dieses aber auch war - es mußte die Frage nach tiefergreifenden sachlichen und ideellen Gemeinsamkeiten, nach der »Tendenz « und dem geistesgeschichtlichen Standort dieser literarischen Gruppe damit notwendig in den Hintergrund drängen. Nach Kleinmayrs mehr philosophisch orientierter Darstellung der Welt- und Kunstanschaunng des Jungen Deutschland aus dem Jahre 1930, mit der sich unsere Analyse zwar thematisch, in der Durchführung aber nur sehr selten berührt, hat erst Walter Dietze versucht, in seinem Buch über Junges Deutschland und deutsche Klassik diesen Zusammenhängen nachzugehen. Doch seine Analyse mußte halten, was sich seine marxistisch orientierte Literaturtheorie davon versprach. So wichtig der Anstoß war, den er damit der Forschung erneut gegeben hat - die Ergebnisse dieses materialreichen Buches bleiben anfechtbar. Dietze hat zudem nur einen besonderen Aspekt ausführlich behandelt: das Verhältnis des Jungen Deutschland zur deutschen Klassik. 


\section{Vorbemerkung}

Vor allem aber: das Junge Deutschland erscheint auch hier so, wie es immer erschienen war: als literarische Gruppe, die ihr Ziel nicht erreicht hat. „Tagesliteratur « ist das immer reichlich despektierliche Schlagwort gewesen, mit dem man das bezeichnete, was unter der Flagge des Jungen Deutschland nach 1830 geschrieben worden war. Daß man die Goethezeit bis ins Detail kennt und die Zeit des Jungen Deutschland im allgemeinen nicht einmal in seinen groben Zügen, hängt mit der für Deutschland charakteristischen, aber allzu fraglosen Hochschätzung der »Klassik« zusammen. Was darauf folgte, gilt nur zu oft als Epigonentum. Immermann hatte diesen Begriff ja selbst nahegelegt.

Die vorliegende Untersuchung möchte das Junge Deutschland von seinem Selbstverständnis her analysieren, nicht von einem Vorher oder Nachher. Sie möchte untersuchen, was die, die sich ihm zugehörig wußten, eigentlich miteinander verband. Die einzelnen Kapitel gehen dabei von sehr verschiedenen Teilphänomenen aus, treffen sich aber im Nachweis der entscheidenden jungdeutschen »Tendenz«. Der Ansatz der Arbeit legte es nahe, die Selbstzeugnisse besonders ausführlich zu berücksichtigen; die Dichtungen sind in sehr viel geringerem Maße herangezogen worden, weniger, weil sie nicht auch aufschlußreich für das Selbstverständnis wären, als vielmehr deswegen, weil sie von vornherein einen anderen, nur mittelbaren Aussagewert haben, der hinter den der unmittelbaren Zeugnisse natürlich zurücktritt. Da die Quellen relativ schlecht zugänglich sind, wurde häufiger aus ihnen zitiert, um die hier vorgetragenen Auffassungen zu belegen, die das einleiten könnten, was C. P. Magill einmal in allerdings anderem Zusammenhang »a revaluation« genannt hat. 